Published in final edited form as:

Org Lett. 2016 September 16; 18(18): 4566-4569. doi:10.1021/acs.orglett.6b02088.

\title{
Alkyne Ligation Handles: Propargylation of Hydroxyl, Sulfhydryl, Amino, and Carboxyl Groups via the Nicholas Reaction
}

\author{
Sarah M. Wells ${ }^{\dagger}$, John C. Widen ${ }^{\ddagger}$, Daniel A. Harki ${ }^{\ddagger},{ }^{,}$, and Kay M. Brummond ${ }^{\dagger,}{ }^{,}$ \\ tDepartment of Chemistry, University of Pittsburgh, Pittsburgh, PA 15206 \\ ‡Department of Medicinal Chemistry, University of Minnesota, Minneapolis, MN 55455
}

\begin{abstract}
The Nicholas reaction has been applied to the installation of alkyne ligation handles. Acidpromoted propargylation of hydroxyl, sulfhydryl, amino, and carboxyl groups using dicobalt hexacarbonyl-stabilized propargylium ions is reported within. This method is especially useful for the introduction of propargyl groups into base-sensitive molecules, thereby expanding the toolbox of methods for the incorporation of alkynes for bioorthogonal reactions. High-value molecules are used as the limiting reagent and various propargylium ion precursors are compared.
\end{abstract}

\section{Graphical Abstract}

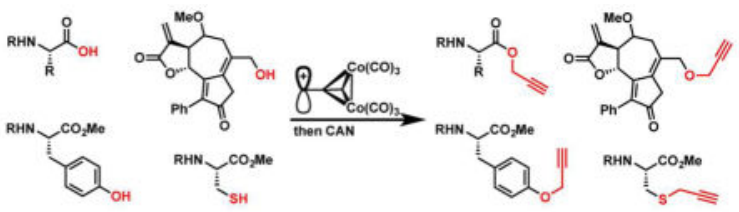

\begin{abstract}
Widespread use of the Huisgen 1,3-dipolar cycloaddition between azides and alkynes to form 1,2,3-triazoles, a click reaction, ${ }^{1}$ has led to increased interest in transformations used to synthesize and/or install alkynyl groups. ${ }^{2}$ Typically, when readying substrates for a click reaction, late-stage propargylation or 5-hexynoylation reactions of hydroxyl or amino groups are used to attach the desired alkynes. ${ }^{2}$ Propargylation of a hydroxyl group is usually achieved by a Williamson ether synthesis under basic conditions where the corresponding alkoxide is reacted with propargyl bromide (Figure 1, eq 1). Src-directed probe 1, was prepared using this approach, but required protection of the $3^{\prime}$ - and $5^{\prime}$-hydroxyl groups and 6-amino group to avoid over-propargylation. ${ }^{3}$ Propargylation has also been accomplished by converting a hydroxyl group into a leaving group (i.e. a mesylate) and replacing it with propargyl amine. ${ }^{4}$
\end{abstract}

\footnotetext{
“Corresponding Author: kbrummon@pitt.edu, daharki@umn.edu.

The authors declare no competing financial interest.

Supporting Information

The SI is available free of charge on the ACS Publications website at DOI: Full experimental details, characterization data, and ${ }^{1} \mathrm{H}$ and ${ }^{13} \mathrm{C}$ NMR spectra for all new compounds (PDF)
} 
Another commonly used protocol for installing an alkynyl group is a carbodiimide-mediated coupling reaction between 5-hexynoic acid and a hydroxyl or amino group (Figure 1, eq 2). ${ }^{2 \mathrm{~b}, 5}$ The Duocarmycin probe 2 exemplifies a product obtained from an $\mathrm{EDC}^{6}$-mediated coupling reaction between a cyclic, secondary amino group and 5-hexynoic acid. ${ }^{7}$ While carbodiimide couplings offer non-basic, neutral conditions, they require expensive reagents and/or the tedious removal of urea-related byproducts.

Many other methods are available for the functionalization of a compound with an alkynyl group ${ }^{2,8}$ however, despite these options, challenges still arise when alkynylating functionally dense natural products and chemical probes for applications such as activitybased protein profiling ${ }^{9}$ for target identification. ${ }^{10}$ For example, during investigations to label two different sesquiterpene analogs with alkynyl groups (vide infra), these analogs were unstable to the basic conditions required for propargylation. Although the hexynoylation reaction could serve as an alternative for appendage of an alkyne ligation handle via an allylic ester linkage, concerns about the metabolic stability of ester-containing probes in cell culture lowered enthusiasm for this approach. ${ }^{11}$ Consequently, a method for propargylation of these sesquiterpene analogs and other biomechanistic probes under nonbasic conditions was needed.

Herein, we report our studies to establish the Nicholas reaction as an alternative protocol for the propargylation of high-value small molecules. The Nicholas reaction involves the addition of a nucleophile to the cobalt-stabilized propargylic carbocation $\mathbf{3}$, generated by treating the corresponding dicobalt hexacarbonyl complexed $\left(\mathrm{Co}_{2}(\mathrm{CO})_{6^{-}}\right)$propargyl alcohol with acid. Alkyne 4 is formed after oxidative decomplexation (Figure 1, eq 3). ${ }^{12}$ While it is well known that the Nicholas reaction can be used to effect propargylation reactions of hetero-nucleophiles, classical conditions require excess nucleophile relative to the cobaltcarbonyl complex, even as the solvent in some cases, limiting its utility in the preparation of alkyne ligation handles. ${ }^{13}$ Conditions where the nucleophile is the limiting reagent would expand the utility of this approach.

With the goal of increasing the efficiency of the Nicholas reaction, we began our reaction condition investigations using molecularly complex alcohol $\mathbf{5}$ as the limiting reagent. Initially, a reaction was carried out with a 1:1.1:1.4 ratio of the nucleophile $\mathbf{5}, \mathbf{6 a}$, and $\mathrm{BF}_{3} \mathrm{OEt}_{2}$ respectively. However, these conditions led to a moderate yield of $40 \%$ so we focused on using higher equivalents of $\mathbf{6} \mathbf{a}$ and $\mathrm{BF}_{3} \mathrm{OEt}_{2}$. We varied the molar equivalencies of complex $\mathbf{6 a}$ and the Lewis-acid $\left(\mathrm{BF}_{3} \mathrm{OEt}_{2}\right)$ while keeping the order of addition constant. To reduce the likelihood of the alcohol and ester groups of 5 tying up the $\mathrm{BF}_{3} \mathrm{OEt}_{2}$, $\mathrm{Co}_{2}(\mathrm{CO})_{6}$-propargyl alcohol 6a was added to $\mathrm{BF}_{3} \mathrm{OEt}_{2}$ to form the propargyl cation, followed by the addition of alcohol 5. Using this addition order and a 1:2:2.5 molar ratio of alcohol 5, complex $\mathbf{6 a}$, and $\mathrm{BF}_{3} \mathrm{OEt}_{2}, \mathrm{Co}_{2}(\mathrm{CO})_{6}$-propargyl ether 7 was obtained in $47 \%$ yield (entry 1) after stirring for $4.5 \mathrm{~h}$ at $0{ }^{\circ} \mathrm{C}$. Increasing the equivalents of $\mathrm{BF}_{3} \mathrm{OEt}_{2}$ and complex $\mathbf{6 a}$ afforded $\mathbf{7}$ in $36 \%$ yield (entry 2). Adding alcohol $\mathbf{5}$ more slowly lowered the yield of 7 to $28 \%$, (entry 3 ).

In view of these unfruitful results, the order of addition was examined. Adding alcohol 5 to $\mathrm{BF}_{3} \mathrm{OEt}_{2}$ prior to addition of complex $\mathbf{6 a}$ did not affect the yield of 7 , obtained in $44 \%$ yield 
(entry 4). Next, alcohol 5 (1 equiv) and $\mathrm{BF}_{3} \mathrm{OEt}_{2}$ (2.5 equiv) were added sequentially to $\mathrm{Co}_{2}(\mathrm{CO})_{6}$-propargyl alcohol 6a (2 equiv), which increased the yield of 7 to $55 \%$ (entry 5). With this same order of addition, increasing the amount of complex $\mathbf{6 a}$ and $\mathrm{BF}_{3} \mathrm{OEt}_{2}$ lowered the yield of $\mathbf{7}$ to $22 \%$ (entry 6). For all of these examples, $\mathbf{6 a}$ was prepared, isolated, and purified, by column chromatography, before the reaction. While it is recognized that this complex is stable to air and moisture, it was reasoned that forming $\mathbf{6 a}$ in situ may be advantageous. ${ }^{13 \mathrm{c}}$ To this end, complex $\mathbf{6 a}$ was formed in situ from propargyl alcohol and dicobalt octacarbonyl, followed by the sequential addition of alcohol $\mathbf{5}$ and $\mathrm{BF}_{3} \mathrm{OEt}_{2}$ to afford the highest yield of 7 (60\%, entry 7). A final attempt to improve the reaction conditions by lowering the reaction temperature only resulted in decreased yields of $7 .{ }^{14}$ Decomplexation of cobalt complex 7 was achieved using ceric ammonium nitrate (CAN) in acetone to readily afford alkyne $\mathbf{8}$ in $97 \%$ yield without the need for purification (Scheme 1). Use of $N$-methylmorpholine- $N$-oxide (NMO) as an oxidant in this transformation resulted in decomposition of $7 .^{15}$

Next, the generality of these optimized reaction conditions was tested on hydroxyl, sulfhydryl, amino, and carboxyl containing amino acids; a class of compounds selected for their richness of functionality and the utility of propargylated peptides for biochemical applications. ${ }^{1 \mathrm{~d}, 2 \mathrm{a}, 16}$ Unfortunately, when subjecting $N$-Boc-L-serine methyl ester (9a) to the optimized reaction conditions, 10a was obtained in $20 \%$ yield while $76 \%$ of the starting material 9a was recovered (Table 2, entry 1). Similarly, when $N$-Fmoc-L-serine methyl ester (9b) was subjected to the same conditions, 10 b was isolated in 29\% yield with $63 \%$ recovered $9 \mathbf{b}$ (entry 3 ). In both of these examples, $\mathrm{Co}_{2}(\mathrm{CO})_{6}$-propargyl alcohol $\mathbf{6 a}$ was fully consumed and the dimerized $\mathrm{Co}_{2}(\mathrm{CO})_{6}$-propargyl alcohol was obtained, resulting from the propargylium cation reacting more readily with the hydroxyl group of $6 \mathbf{a}$. To overcome this competing homodimerization reaction, $\mathrm{Co}_{2}(\mathrm{CO})_{6}$-methyl propargyl ether $\mathbf{6 b}$ was examined. ${ }^{12 \mathrm{c}}$ Reaction of $N$-Boc-L-serine methyl ester (9a) with $\mathbf{6 b}$ afforded 10a in $97 \%$ yield (entry 2). The yield of $\mathbf{1 0 b}$ also increased significantly to $54 \%$ when using complex $\mathbf{6 b}$ (entry 4). Use of propargyl acetate for the synthesis of $\mathbf{1 0 a}$ and $\mathbf{1 0 b}$ gave yields comparable to complex 6a (See Supporting Information (SI)).

Next, we tested this method for the propargylation of cysteine thiols, a transformation typically accomplished using basic alkylation conditions. ${ }^{2 a, 17}$ Thiols react efficiently in the Nicholas reaction; however, application has been limited to the synthesis of sulfur containing macrocycles. ${ }^{12 c, 18} \mathrm{~N}$-acetyl- and $\mathrm{N}$-Fmoc-L-cysteine ethyl ester $(\mathbf{9 c}$ and $\mathbf{9 d})$ were reacted with complex 6a giving the corresponding $\mathrm{Co}_{2}(\mathrm{CO})_{6}$-alkynes $10 \mathrm{c}$ and $10 \mathrm{~d}$ in high yields of $86 \%$ and $71 \%$ (Entries 5,6). $N$-Fmoc cysteine 9d was also reacted with methyl propargyl ether complex $\mathbf{6 b}$, which gave a comparable yield of $67 \%$ for $10 \mathrm{~d}$ (entry 7 ).

To evaluate the phenolic side chain of tyrosine in the Nicholas reaction, $N$-Boc-L-tyrosine methyl ester (9e) was reacted with complex 6a. ${ }^{13 a}$ Two major products were observed; the desired product, 10e, was isolated in $45 \%$ yield (57\% based on recovered 9e) (entry 8), while an unstable byproduct was obtained in trace amounts. ${ }^{1} \mathrm{H}$ NMR analysis of this byproduct revealed aromatic signals integrating for three protons, resulting from electrophilic aromatic substitution (see SI, S5). ${ }^{12 \mathrm{c}}$ Because $9 \mathrm{e}$ was recovered along with 
complete consumption of $\mathbf{6 a}$, complex $\mathbf{6 b}$ was tested. This reaction required a longer reaction time and did not improve the yield of $10 e$ (23\% yield, entry 9) due to Boc instability. ${ }^{19}$ When the $N$-Fmoc tyrosine ester 9 f was reacted with complex 6a, 10 f was formed in $6 \%$ yield (56\% based on recovered starting material) (entry 10). Employing complex $\mathbf{6 b}$ resulted in a significantly improved yield to $73 \%$ (entry 11). A byproduct, presumably formed by electrophilic aromatic substitution, was also observed by TLC for these reactions.

Amino groups were tested by subjecting L-proline methyl ester $(\mathbf{9 g})$ to the Nicholas reaction with 6a. Consumption of $\mathbf{9 g}$ was observed by TLC within $15 \mathrm{~min}$ with no evidence of $\mathbf{1 0 g}$ (entry 12). We presume the $\mathrm{BF}_{3} \mathrm{OEt}_{2}$ coordinates with the nitrogen of proline. To circumvent this issue, the cationic propargylium ion was prepared as tetrafluoroborate salt $\mathbf{6 c}$ by reacting complex $6 \mathbf{a}$ with tetrafluoroboric acid in diethyl ether at $0{ }^{\circ} \mathrm{C} .{ }^{12 b, 20}$ Reaction of $\mathbf{6 c}$ with proline ester $9 \mathrm{~g}$ in DCM at $0^{\circ} \mathrm{C}$ afforded $\mathrm{Co}_{2}(\mathrm{CO})_{6}$-alkyne $10 \mathrm{~g}$ in $46 \%$ yield (entry 13 ). The primary amine of L-phenylalanine methyl ester $(\mathbf{9 h})$ also proved to be an effective nucleophile; when reacted with $\mathbf{6 c}$, dialkylation afforded amine $\mathbf{1 0 h}$ in $59 \%$ yield (entry 14).

Carboxyl groups were also subjected to the Nicholas reaction conditions. Only a few examples of carboxyl groups serving as a nucleophile in the Nicholas reaction have been reported. ${ }^{21}$ Reaction of $\mathrm{N}$-Bz-D-phenylalanine (9i) with complex $\mathbf{6 a}$ and $\mathrm{BF}_{3} \mathrm{OEt}_{2}$ afforded $\mathrm{Co}_{2}(\mathrm{CO})_{6}$-propargyl ester $10 \mathbf{i}$ in $60 \%$ yield (entry 15$)$. Reaction of $9 \mathbf{i}$ with complex $\mathbf{6 c}$ afforded a lower yield for $\mathbf{1 0 i}$ (18\%, entry 16$)$; thus, the utility of preformed propargylium salt is not necessarily general.

$\mathrm{Co}_{2}(\mathrm{CO})_{6}$-alkyne modified amino acids 10a-j underwent oxidative decomplexation with CAN. The propargyl derivatives of serine, cysteine, tyrosine, and phenylalanine 11a-f, $\mathbf{i}$ were afforded in high yields (75-94\%). A moderate yield of 56\% was observed for the formation of dipropargylamine 11h (entry 14). Proline alkyne derivative 11g appeared to be unstable, permitting isolation and NMR characterization only once prior to decomposition (entry 12).

To effect mono-alkynylation of primary amines, an alternative tetrafluoroborate salt $\mathbf{1 2}$ was prepared from $\mathrm{Co}_{2}(\mathrm{CO})_{6}$-2-methyl-3-butyn-2-ol (Scheme 2). Reaction of 12 with phenylalanine ester $\mathbf{9 h}$ afforded the mono-alkynylated propargyl amine $\mathbf{1 3}$ after oxidative decomplexation.

Finally, to show the synthetic utility of these conditions for base-sensitive, functionally dense molecules we applied the Nicholas reaction conditions to two sesquiterpene analogs. Base-sensitive guaianolide analog 14, previously synthesized in our group, was reacted with $\mathrm{Co}_{2}(\mathrm{CO})_{6}$-propargyl alcohol $\mathbf{6 a}$, formed in situ, and $\mathrm{BF}_{3} \mathrm{OEt}_{2}$, to give the $\mathrm{Co}_{2}(\mathrm{CO})_{6}$-alkyne derivative in $46 \%$ yield. ${ }^{22}$ Reaction with CAN generated alkyne probe $\mathbf{1 5}$ in quantitative yield.

Melampomagnolide B (MelB) (16) has been used as a parthenolide mimic for conjugation to biotin via an ester-linkage. ${ }^{23,24}$ However, these biotinylated compounds may have metabolic stability issues for in vivo biochemical experiments. Formation of the alternative ether linkage using the allylic alcohol handle has proven to be difficult; MelB is base sensitive and 
the allylic hydroxyl group was unreactive in our hands towards oxidation or bromination. ${ }^{25}$ Reaction of MelB (16) with $\mathrm{Co}_{2}(\mathrm{CO})_{6}$-propargyl alcohol complex $\mathbf{6 a}$ and $\mathrm{BF}_{3} \mathrm{OEt}_{2}$ afforded the corresponding $\mathrm{Co}_{2}(\mathrm{CO})_{6}$-alkyne product after $1 \mathrm{~h}$ in $19 \%$ yield. A shortened reaction time of 10 min gave a $41 \%$ yield (45\% yield based on recovered 16), suggesting the $\mathrm{Co}_{2}(\mathrm{CO})_{6}$-alkyne product was unstable to the reaction conditions. Reacting MelB (16) with $\mathrm{Co}_{2}(\mathrm{CO})_{6}$-methyl propargyl ether $\mathbf{6} \mathbf{b}$ gave a $39 \%$ yield of the coupled product. Cobalt decomplexation afforded the MelB alkyne probe $\mathbf{1 7}$ in $94 \%$ yield (Scheme 3).

In conclusion, the Nicholas reaction conditions described provide an acid-mediated alternative for propargylation of molecularly complex compounds. Reaction conditions were optimized for use of high-value nucleophiles as limiting reagents, a practice atypical for the Nicholas reaction. A number of functional groups acted as the nucleophilic species, including hydroxyl, sulfhydryl, carboxyl, and amino groups. For substrates that react slower than the competing dimerization of $\mathrm{Co}_{2}(\mathrm{CO})_{6}$-propargyl alcohol 6a, use of methyl propargyl ether complex $\mathbf{6 b}$ improved yields. Propargylation of amino groups required the preparation of propargylium tetrafluoroborate salts. Mono- and di-alkynylation of a primary amino group was achieved selectively depending on the steric nature of the propargylium ion. Bz, $\mathrm{Cbz}, \mathrm{Ac}$, and Fmoc amine protecting groups were all tolerated. Finally, these conditions provided an alternative propargylation strategy for base-sensitive sesquiterpene analogs.

\section{Supplementary Material}

Refer to Web version on PubMed Central for supplementary material.

\section{Acknowledgments}

We gratefully acknowledge the NIH (R21-CA194661 to DAH and R01-GM054161 to KMB) and the Department of Defense (PC141033 to DAH) for funding. Mass spectrometry performed at the University of Minnesota was conducted at the Masonic Cancer Center Analytical Biochemistry Core Facility, which is supported by the National Institute of Health (P30-CA77598).

\section{References}

1. (a) Rostovtsev VV, Green LG, Fokin VV, Sharpless KB. Angew Chem Int Ed. 2002; 41:2596-2599. (b) Meldal M, Tornoe CW. Chem Rev. 2008; 108:2952-3015. [PubMed: 18698735] (c) Sletten EM, Bertozzi CR. Angew Chem Int Ed. 2009; 48:6974-6998.(d) Tang W, Becker ML. Chem Soc Rev. 2014; 43:7013-7039. [PubMed: 24993161] (e) Martell J, Weerapana E. Molecules. 2014; 19:13781393. [PubMed: 24473203] (f) Tiwari VK, Mishra BB, Mishra KB, Mishra N, Singh AS, Chen X. Chem Rev. 2016; 116:3086-3240. [PubMed: 26796328]

2. (a) Johansson H, Pedersen DS. Eur J Org Chem. 2012:4267-4281.(b) Lehmann J, Wright MH, Sieber SA. Chem Eur J. 2016; 22:4666-4678. [PubMed: 26752308]

3. Gushwa NN, Kang S, Chen J, Taunton J. J Am Chem Soc. 2012; 134:20214-20217. [PubMed: 23190395]

4. Cohen MS, Hadjivassiliou H, Taunton J. Nat Chem Biol. 2007; 3:156-160. [PubMed: 17259979]

5. For selected examples, see: Bottcher T, Sieber SA. J Am Chem Soc. 2010; 132:6964-6972.

[PubMed: 20433172] Kalesh KA, Sim DSB, Wang J, Liu K, Lin Q, Yoa SQ. Chem Commun. 2010; 46:1118-1120.Krysiak JM, Kreuzer J, Macheroux P, Hermetter A, Sieber SA, Breinbauer R. Angew Chem Int Ed. 2012; 51:7035-7040.Kreuzer J, Bach NC, Forler D, Sieber SA. Chem Sci. 2015; 6:237-245.

6. 1-ethyl-3-(3-dimethylaminopropyl)carbodiimide. 
7. Wirth T, Pestel GF, Ganal V, Kirmeier T, Schuberth I, Rein T, Tietze LF, Sieber SA. Angew Chem Int Ed. 2013; 52:6921-6925.

8. For a C-H functionalization strategy, see: Li J, Cisar JS, Zhou C-Y, Vera B, Williams H, Rodriguez AD, Cravatt BF, Romo D. Nat Chem. 2013; 5:510-517. [PubMed: 23695633]

9. For selected reviews on ABPP, see: Cravatt BF, Wright AT, Kozarich JW. Annu Rev Biochem. 2008; 77:383-414. [PubMed: 18366325] Nodwell MB, Sieber SA. ABPP Methodology: Introduction and Overview. Activity-Based Protein Profiling. :1.Sieber SA. SpringerBerlin Heidelberg2012; 324 141.Willems LI, Overkleeft HS, van Kasteren SI. Bioconjug Chem. 2014; 25:1181-1191. [PubMed: 24946272] Yang P, Liu K. ChemBioChem. 2015; 16:712-724. [PubMed: 25652106]

10. (a) Bottcher T, Pitscheider M, Sieber SA. Angew Chem Int Ed. 2010; 49:2680-2698.(b) Su Y, Ge J, Zhu B, Zheng YG, Zhu Q, Yao SQ. Cur Opin Chem Biol. 2013; 17:768-775.

11. (a) Ettmayer P, Amidon GL, Clement B, Testa B. J Med Chem. 2004; 47:2393-2404. [PubMed: 15115379] (b) Li B, Sedlacek M, Manoharan I, Boopathy R, Duysen EG, Masson P, Lockridge O. Biochem Pharmacol. 2005; 70:1673-1684. [PubMed: 16213467]

12. Lockwood RF, Nicholas KM. Tetrahedron Lett. 1977; 18:4163-4165.for reviews on the Nicholas Reaction, see: Nicholas KM. Acc Chem Res. 1987; 20:207-214.Teobald BJ. Tetrahedron. 2002; 58:4133-4170.Diaz DD, Betancort JM, Martin VS. Synlett. 2007:343-359.

13. (a) Diaz DD, Martin VS. Tetrahedron Lett. 2000; 41:9993-9996.(b) Hope-Weeks LJ, Mays MJ, Solan GA. Eur J Inorg Chem. 2007:3101-3114.(c) Ortega N, Martin VS, Martin T. J Org Chem. 2010; 75:6660-6672. [PubMed: 20809659]

14. Reactions at $-40{ }^{\circ} \mathrm{C}$ and $-10{ }^{\circ} \mathrm{C}$ afforded 7 in $23 \%$ and $38 \%$ yield, respectively.

15. Hayashi Y, Yamaguchi H, Toyoshima M, Okado K, Toyo T, Shoji M. Chem Eur J. 2010; 16:10150-10159. [PubMed: 20645347]

16. Ahmad Fuaad A, Azmi F, Skwarczynski M, Toth I. Molecules. 2013; 18:13148-13174. [PubMed: 24284482]

17. Struthers H, Spingler B, Mindt TL, Schibli R. Chem Eur J. 2008; 14:6173-6183. [PubMed: 18494020]

18. For selected examples, see: Hope-Weeks LJ, Mays MJ, Woods AD. J Chem Soc, Dalton Trans. 2002:1812-1819.Hagendorn T, Brase S. RSC Adv. 2014; 4:15493-15495.

19. Evans EF, Lewis NJ, Kapfer I, Macdonald G, Taylor RJK. Synth Commun. 1997; 27:1819-1825.

20. Amouri H, Begue J-P, Chennoufi A, Bonnet-Delpon D, Gruselle M, Malezieux B. Org Lett. 2000; 2:807-809. [PubMed: 10814433]

21. Shea KM, Closser KD, Quintal MM. J Org Chem. 2005; 70:9088-9091. [PubMed: 16238362]

22. Wen B, Hexum JK, Widen JC, Harki DA, Brummond KM. Org Lett. 2013; 15:2644-2647. [PubMed: 23662902]

23. (a) Macias FA, Galindo JCG, Massanet GM. Phytochemistry. 1992; 31:1969-1977.(b) Nasim S, Pei S, Hagen FK, Jordan CT, Crooks PA. Bioorg Med Chem. 2011; 19:1515-1519. [PubMed: 21273084]

24. (a) Kwok BHB, Koh B, Ndubuisi MI, Elofsson M, Crews CM. Chem Biol. 2001; 8:759-766. [PubMed: 11514225] (b) Janganati V, Penthala NR, Madadi NR, Chen Z, Crooks PA. Bioorg Med Chem Lett. 2014; 24:3499-3502. [PubMed: 24928404]

25. Attempts to manipulate the allylic alcohol of 17 included use of: PCC, PDC, Dess-Martin periodinane, and $\mathrm{PBr}_{3}$.

Org Lett. Author manuscript; available in PMC 2017 September 16. 
Previous Work

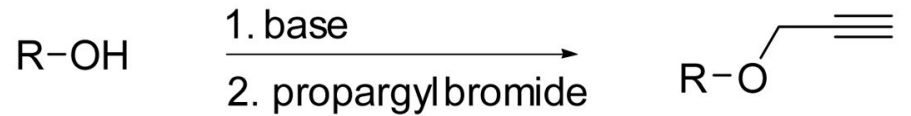

hexynoic acid

$\mathrm{R}-\mathrm{XH} \quad \frac{\text { carbodiimide coupling }}{\mathrm{X}=\mathrm{O}, \mathrm{NH}}$<smiles>[R][X]C(=O)C#CC#C</smiles><smiles>C#CCO[C@H]1[C@H](O)[C@@H](COS(=O)(=O)C=C)O[C@H]1n1cc(-c2ccc(C)cc2)c2c(N)ncnc21</smiles>

Src-directed probe 1<smiles>C#CCCCC(=O)N1C[C@H](CCl)c2c1cc(O)c1ccccc21</smiles>

Duocarmycin probe 2

\section{This Work}

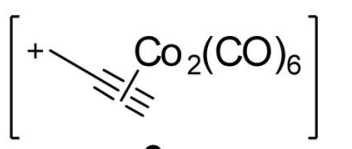

3
1. $\mathrm{R}-\mathrm{XH}$

2. CAN, acetone 15 examples

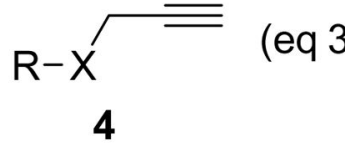

Figure 1.

Synthetic methods for alkyne incorporation. 


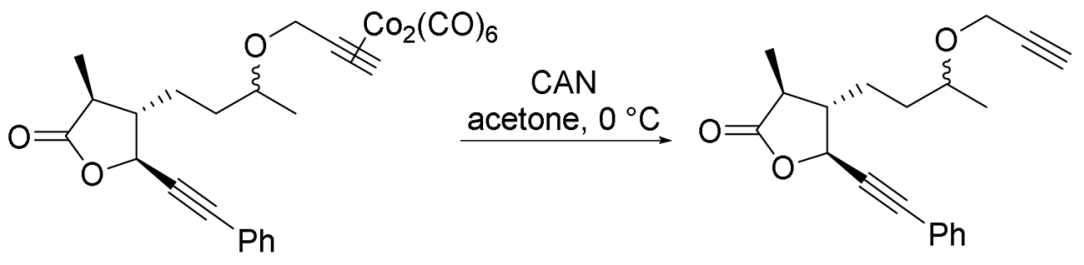

7

8, $97 \%$

Scheme 1.

Decomplexation of $\mathrm{Co}_{2}(\mathrm{CO})_{6}$-alkyne 7 . 

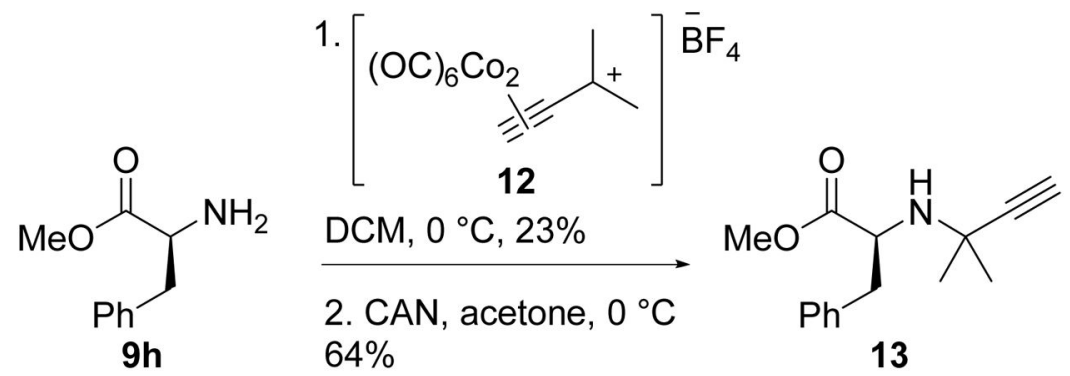

Scheme 2

Reaction of primary amine $9 \mathrm{~h}$ with $\mathrm{BF}_{4}{ }^{-}$salt 12 . 

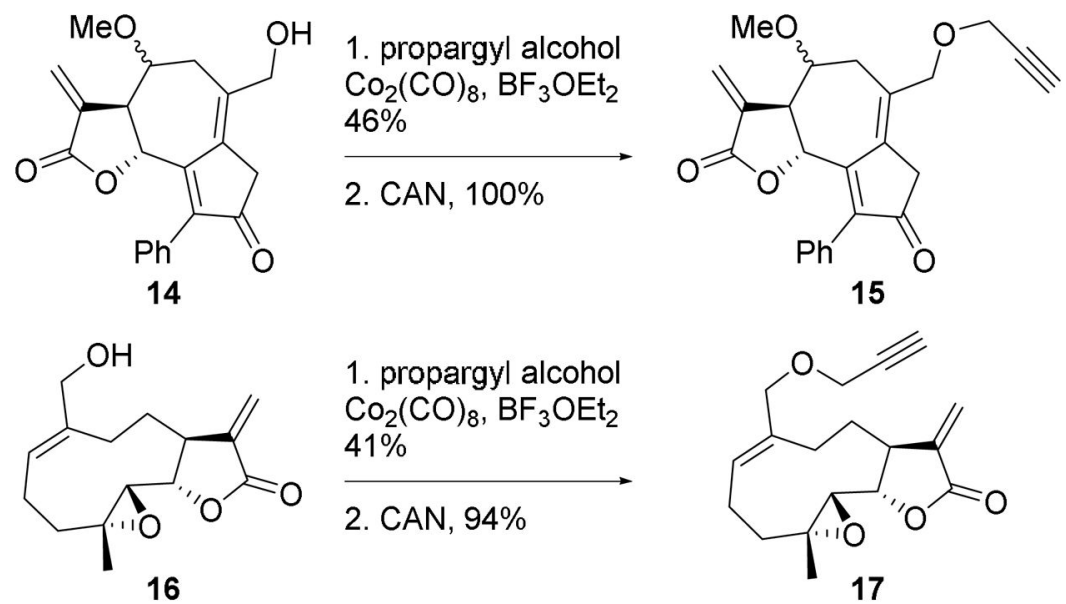

Scheme 3.

Synthesis of alkyne probes 15 and 17. 

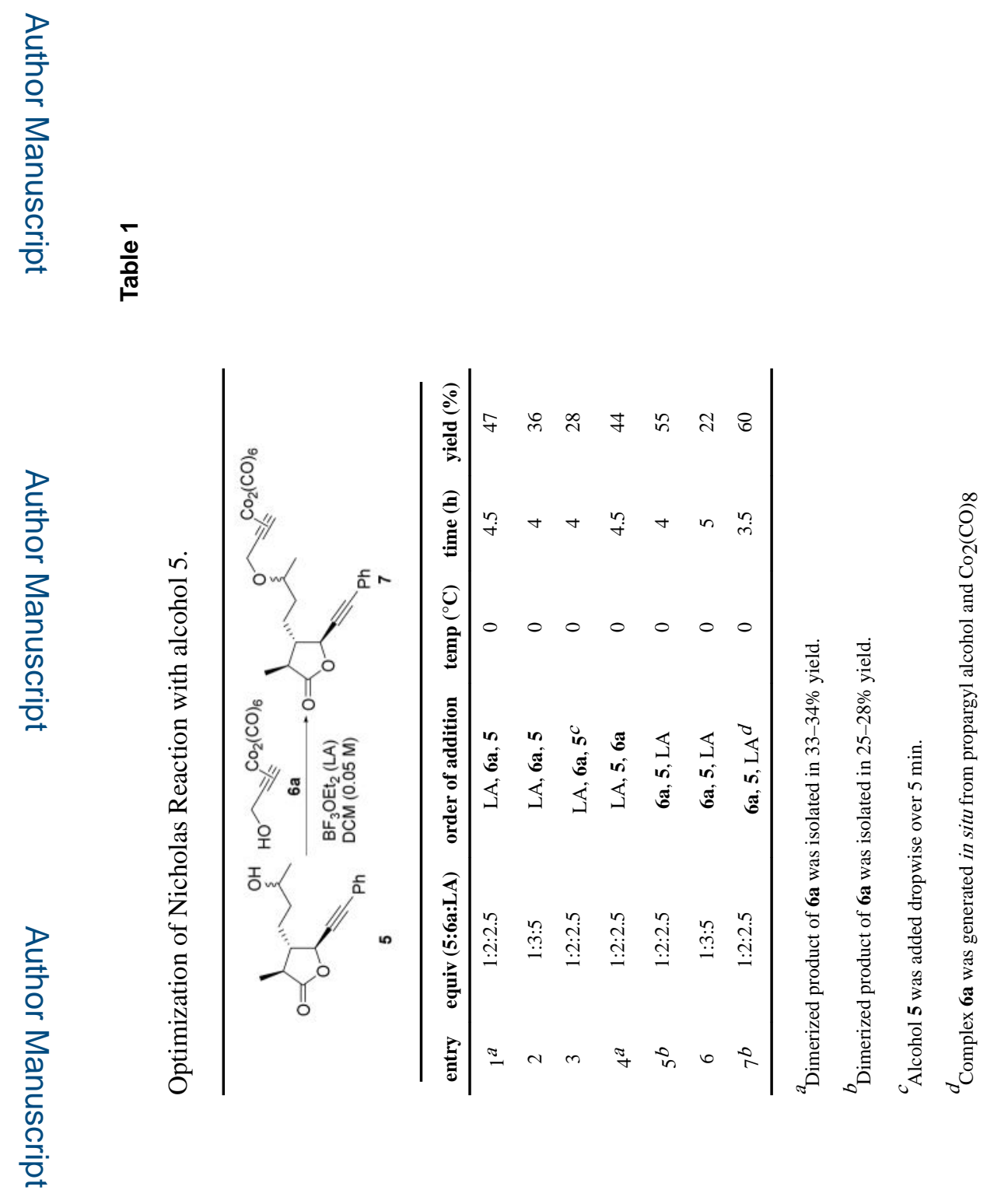

Org Lett. Author manuscript; available in PMC 2017 September 16. 


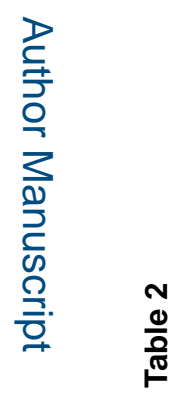

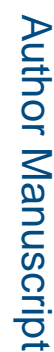

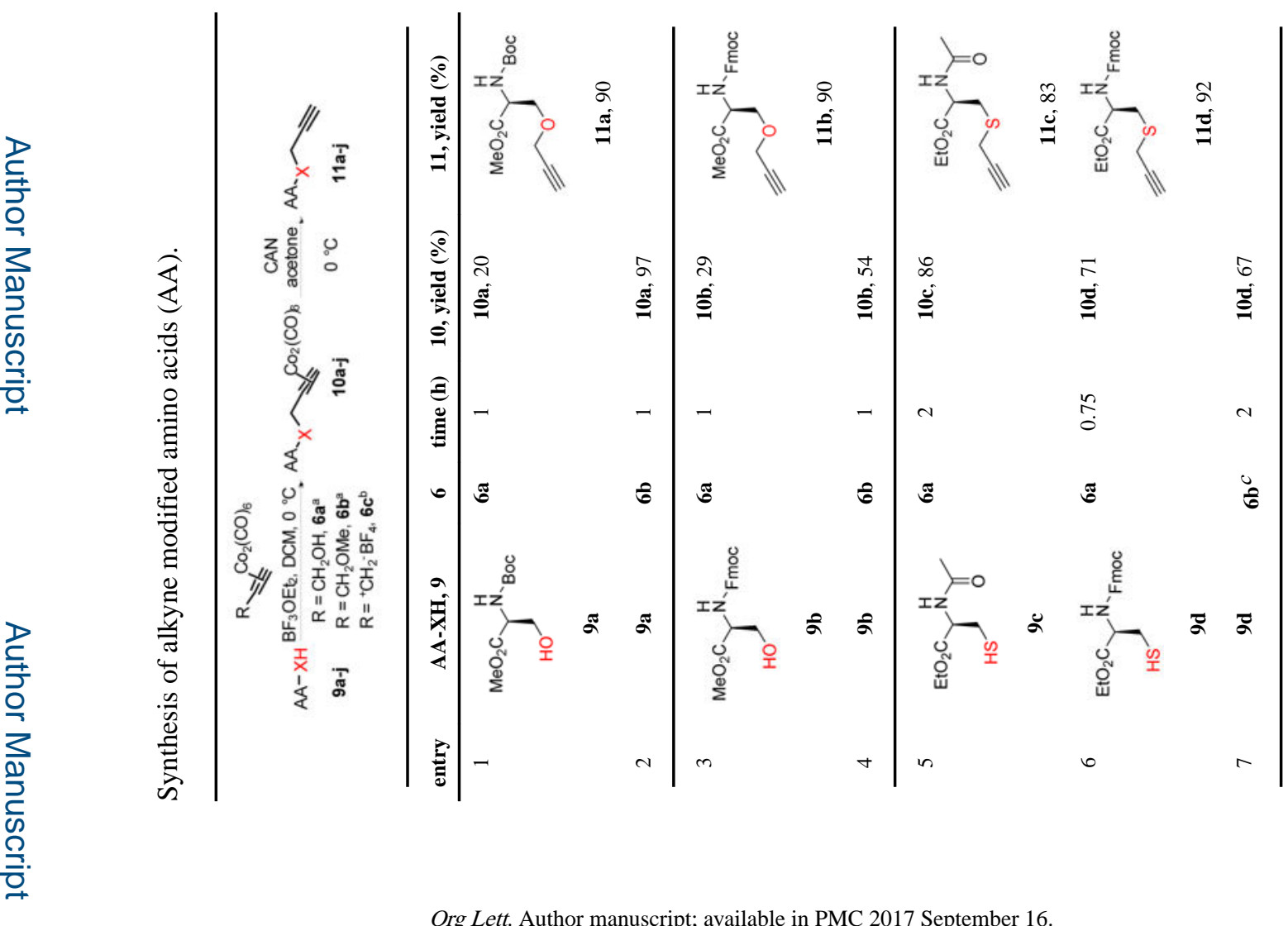

를 
Wells et al.

Page 13

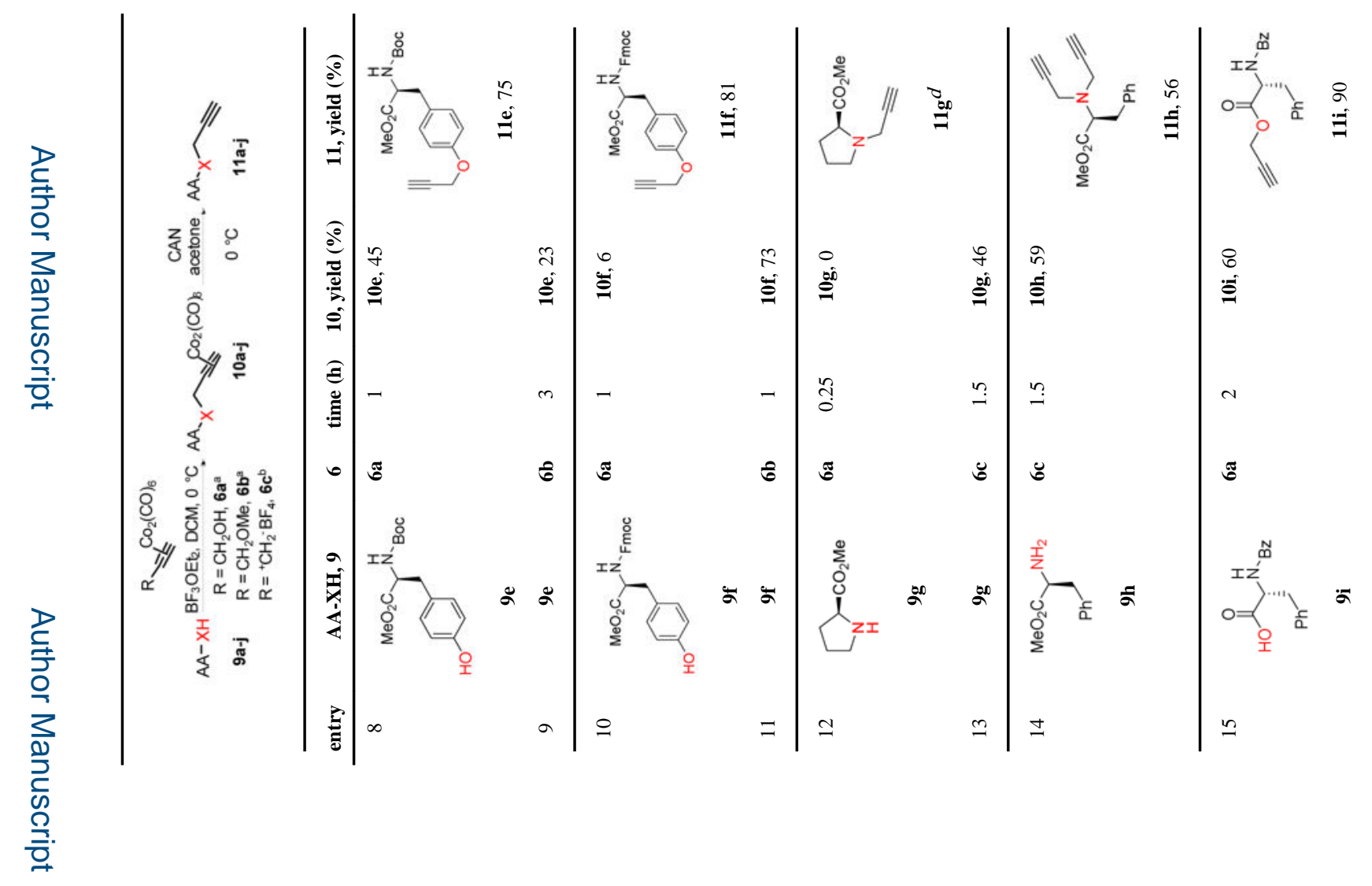

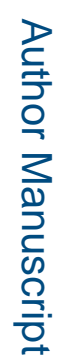

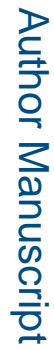

Org Lett. Author manuscript; available in PMC 2017 September 16. 


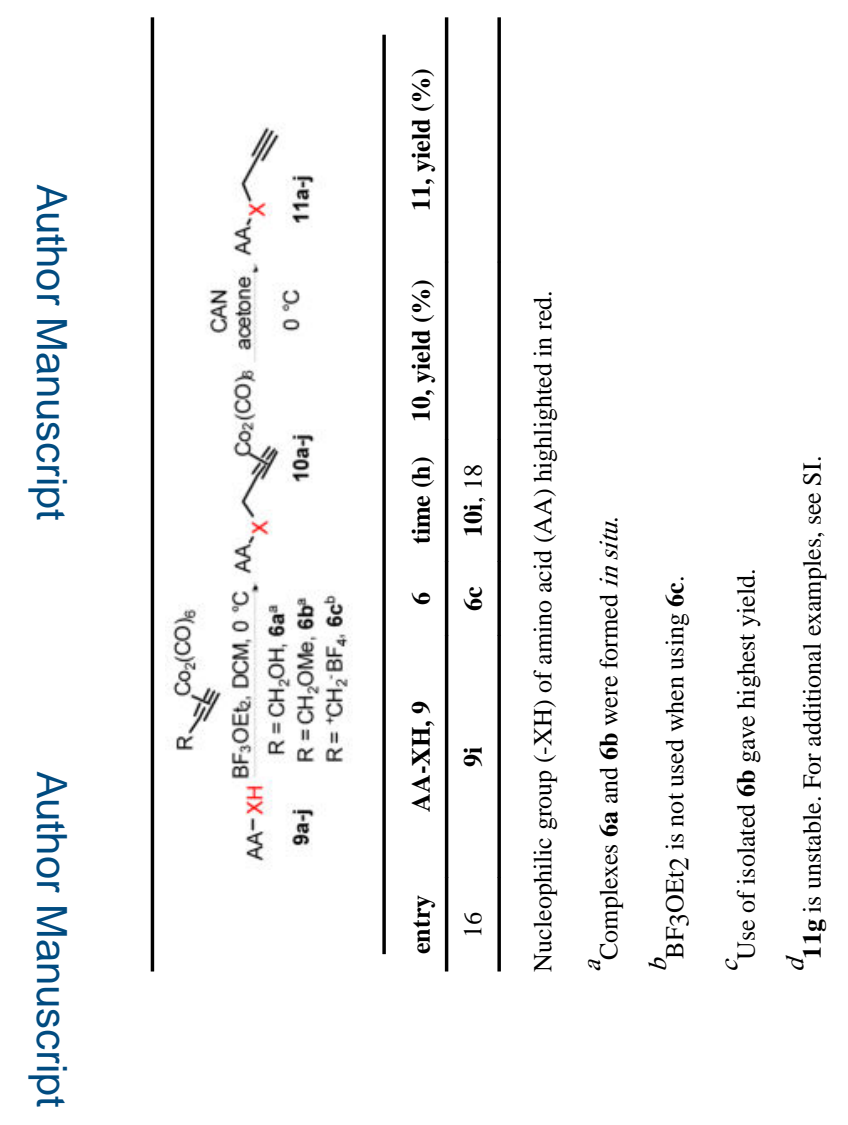

로을

로을

Org Lett. Author manuscript; available in PMC 2017 September 16. 